\title{
Health, cognitive, and psychosocial factors as predictors of mortality in an elderly community sample
}

\author{
A E Korten, A F Jorm, Z Jiao, L Letenneur, P A Jacomb, A S Henderson, H Christensen, \\ B Rodgers
}

\begin{abstract}
Study objective-To examine whether cognitive and psychosocial factors predict mortality once physical health is controlled.

Design-A prospective study of community dwelling elderly. Mortality was assessed over a period of 3-4 years after the baseline assessment of predictors. The data were analysed using the Cox proportional hazards model.

Setting-Canberra and Queanbeyan, Australia.

Participants-A sample of 897 people aged 70 or over and living in the community, drawn from the compulsory electoral roll. Results-For the sample as a whole, the significant predictors of mortality were male sex, poor physical health, poor cognitive functioning, and low neuroticism. Men had an adjusted relative risk of mortality of 2.5 compared with women. For the male sub-sample, poor self rated health and a poor performance on a speeded cognitive task were significant predictors, while for women, greater disability, low systolic blood pressure, and a low score on a dementia screening test were the strongest predictors.

Conclusions-Mortality was predicted by physical ill health and poor cognitive functioning. Psychosocial factors such as socioeconomic status, psychiatric symptoms, and social support did not add to the prediction of mortality, once sex, physical health, and cognitive functioning were controlled. Mortality among men was more than twice that of women, even when adjusted for other predictors.

(F Epidemiol Community Health 1999;53:83-88)
\end{abstract}

There is now an extensive literature examining predictors of mortality in samples of the general population, particularly in the elderly. Much interest has centred on whether psychosocial factors are predictors of mortality once physical health is controlled.

While physical diseases are clearly the main predictors of mortality, there has been much interest in self rated health. Single questions that ask the respondent about their global health can predict mortality better than more complex physical health measures. ${ }^{1}$ Furthermore, self rated health tends to predict better for men than women. The reasons for this strong association are only partly understood. ${ }^{1}$
Poor cognitive functioning has been found to be a predictor in several studies. ${ }^{2-7}$ Some of the excess mortality is probably caused by dementing diseases and their complications, but an association has been found even when demented subjects are excluded, retaining those with sub-clinical cognitive impairment. ${ }^{4}$ Perhaps the most interesting issue now is which aspects of cognitive functioning are the best predictors. For example, one recent study implicated mental speed. ${ }^{3}$

Social support is one of the most extensively researched psychosocial factors. There are now a large number of studies showing that a low level of social support predicts mortality, ${ }^{5-15}$ although other studies have failed to find an association. ${ }^{16-19}$ The mechanism of this association is not understood.

There is mixed evidence about common psychiatric disorders as predictors of mortality. Most of the work has been done with depression or with scales of neurotic symptoms. Controlling for physical health is very important when studying psychiatric disorders and symptoms, because physical ill health and disability are known risk factors for depression. ${ }^{20}$ When physical health is controlled, some studies have found an association with mortality, ${ }^{21-23}$ but others have been negative. ${ }^{5} 1824$ The mixed findings may have resulted because some studies have included more comprehensive measures of physical health than others. Another explanation is that psychiatric disorders predict mortality only over shorter follow up periods. ${ }^{22}$

Personality has received comparatively little attention as a predictor of mortality. Currently, the most popular model of personality traits is the five factor model that posits factors of extraversion, neuroticism, conscientiousness, agreeableness, and openness/intellect. There is evidence that neuroticism and extraversion are not predictors of mortality, ${ }^{22}{ }^{25}$ but one study found an association with low conscientiousness. ${ }^{26}$

Low socioeconomic status has been linked to mortality from a wide range of causes. ${ }^{27}$ Socioeconomic differences in health behaviours are responsible for some, but not all, of these differences. ${ }^{27}$

Health behaviours can also be broadly grouped under psychosocial factors. While smoking is a well known risk factor for mortality, the evidence in the elderly shows both positive $\mathrm{e}^{1419}$ and non-significant results. $^{23512}$ This may be because elderly 
smokers are a survival élite. Physical activity has also been investigated, with both positive ${ }^{28}$ and non-significant results. ${ }^{12}$

Most studies tend to focus on only one type of psychosocial factor. Here we report on a study that allows the simultaneous investigation of a variety of psychosocial and cognitive factors as predictors of mortality while controlling for physical health. Baseline information included physical health (including self rated health), cognitive functioning, common psychiatric symptoms, social support, personality, socioeconomic status, and health behaviours.

\section{Method}

THE SAMPLE

The sample has been described in detail elsewhere. ${ }^{29}$ Briefly, the subjects were 456 men and 441 women, aged 70 or over at the time of baseline assessment and living in the community in Canberra or Queanbeyan, Australia. The subjects were sampled from the compulsory electoral roll with a response rate of $69 \%$.

ASSESSMENT OF MORTALITY

Predictor variables were assessed in 1990 1991 and then surviving subjects were reinterviewed in 1994. Dates of any intervening deaths were established by contacting relatives, from searching the National Death Index maintained by the Australian Institute of Health and Welfare, and from death notices in the local newspaper. Mortality status was established for all but 10 respondents. Survival was calculated as the number of days from the time of Wave 1 assessment to either death or Wave 2 assessment. For the three men and three women known to have died, but for whom no date of death was available, a survival of 650 days was assigned, being the median survival of those who died.

ASSESSMENT OF PREDICTOR VARIABLES

The predictor variables were organised into separate blocks as follows.

Physical health

Physical health was assessed in several ways as described previously. ${ }^{30}$ Global self rated health was assessed by asking "Would you say your overall health nowadays is excellent, good, fair or poor?" A count was made of 21 common symptoms (for example, cramps, breathing difficulties, indigestion, headaches) occurring in the past month. A count was also made of reported diseases from a list of 28 items, such as heart attacks, high blood pressure, diabetes, thyroid dysfunction, cancers. Disability was assessed by a scale of activities of daily living. Subjects were asked how often they had experienced pain in the past month $(1=$ never to $6=$ constantly). Measures of hearing and visual impairment were derived from the subject ratings of how well they could see and hear in different situations. Scores ranges from 5 to 16 with higher scores indicating greater impairment. Blood pressure was measured twice a few minutes apart, the results averaged and the categories constructed of systolic hypertensives $(140+\mathrm{mm} \mathrm{Hg})$, normotensives (120-139 mm
$\mathrm{Hg}$ ), and hypotensives $(<120 \mathrm{~mm} \mathrm{Hg}$ ); and diastolic hypertensives (>85 mm Hg), normotensives $(75-85 \mathrm{~mm} \mathrm{Hg}$ ), and hypotensives (<75 mm Hg). ${ }^{31}$

\section{Cognitive functioning}

Four tests assessed various aspects of cognitive functioning: a brief screening test for dementia, the Mini-Mental State Examination $(\mathrm{MMSE})^{32}$; the Episodic Memory Test, which consists of four short memory tasks ${ }^{33}$; the Symbol-Letter Modalities Test (SLMT), which is a measure of cognitive speed ${ }^{34}$; and the National Adult Reading Test (NART), a test of crystallised intelligence that relies on the reading of words that are not pronounced phonetically. ${ }^{35}$

\section{Social support}

Subjects were classified as living alone or with others. There were also three social support scales measuring the extent of the subject's social network (Network), the availability of help if needed (Help Available), and the availability of close and confiding relationships (Close Friends). These were derived from a short form of the Interview Schedule for Social Interaction (ISSI), which included items covering the availability of social integration, the availability of attachments, the adequacy of social integration and some additional items on the availability of proximate help that were particularly relevant to the elderly. ${ }^{36}$

\section{Psychiatric symptoms}

Subjects were assessed with the Scale for Depressive Symptoms, ${ }^{29}$ the number of depression symptoms out of a possible 28 , which are used in diagnostic algorithms, and the Goldberg Anxiety and Depression Scales, which are counts of nine symptoms of depression and nine of anxiety. ${ }^{37}$

\section{Personality}

Subjects completed the Extraversion and Neuroticism scales of the short form of the Eysenck Personality Questionnaire-Revised. ${ }^{38}$ Each scale consists of the count of positive responses to 12 questions about how a respondent usually behaves, feels or acts.

\section{Socioeconomic status}

Socioeconomic status was measured by years of education and by an ordinal occupational status scale that ranged from 1: semi or unskilled to 5: managerial/professional. Women who were involved in home duties were assigned their husband's occupational status.

\section{Health behaviours}

Subjects were asked whether they currently smoked or had ever smoked. Inactivity was measured by asking respondents how often "these days" they engaged in each of six different activities such as reading a newspaper or physical activity. Responses were summed, with higher scores indicating greater inactivity. ${ }^{39}$ 


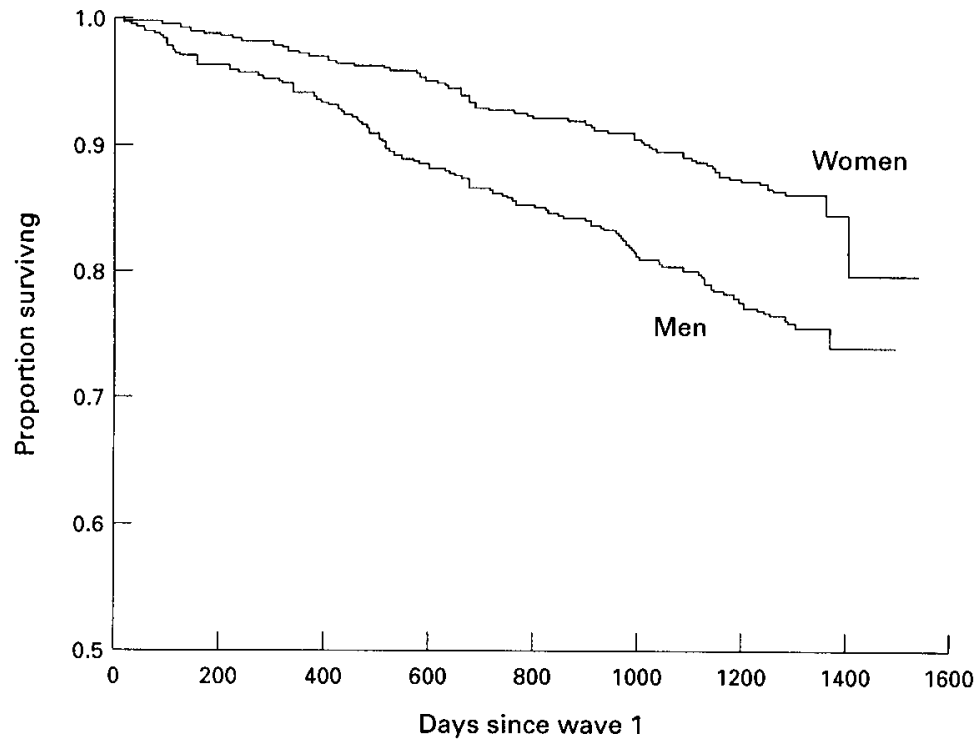

Figure 1 Observed Kaplan-Meier survival curves for men and women separately. Table 1 Predictor variables at Wave 1. Those alive at Wave 2 compared with those who died between waves

\begin{tabular}{|c|c|c|c|}
\hline & $\begin{array}{l}\text { Alive Mean (SD) } \\
\text { or } \%(n=623-715)\end{array}$ & $\begin{array}{l}\text { Died Mean (SD) } \\
\text { or \% }(n=129-172)\end{array}$ & $\begin{array}{l}p \text { value }(t \\
\left.\text { or } \chi^{2} \text { test }\right)\end{array}$ \\
\hline Age (y) & & & 0.000 \\
\hline $70-74$ & $43.6 \%$ & $33.7 \%$ & \\
\hline $75-79$ & $33.1 \%$ & $28.5 \%$ & \\
\hline $80-84$ & $16.9 \%$ & $22.1 \%$ & \\
\hline $85+$ & $6.3 \%$ & $15.7 \%$ & \\
\hline Sex: \% male & $47.7 \%$ & $64.0 \%$ & 0.000 \\
\hline \multicolumn{4}{|l|}{ Physical health } \\
\hline General health & & & 0.000 \\
\hline Excellent & $19.3 \%$ & $14.0 \%$ & \\
\hline Good & $56.7 \%$ & $45.8 \%$ & \\
\hline Fair & $21.3 \%$ & $25.0 \%$ & \\
\hline Poor & $2.7 \%$ & $15.2 \%$ & \\
\hline Number of current symptoms & $3.2(2.7)$ & $4.4(3.2)$ & 0.000 \\
\hline Number of current illnesses & $2.7(1.3)$ & $3.3(1.2)$ & 0.000 \\
\hline Recent pain & $2.3(1.6)$ & $2.4(1.7)$ & 0.342 \\
\hline Activities of daily living (ADL) & $1.6(2.1)$ & $3.0(3.6)$ & 0.000 \\
\hline Hearing impairment & $8.2(1.8)$ & $8.6(2.0)$ & 0.008 \\
\hline Visual impairment & $7.2(1.3)$ & $7.3(1.7)$ & 0.085 \\
\hline \multicolumn{4}{|l|}{ Systolic blood pressure } \\
\hline Hypotensive & $9.2 \%$ & $15.3 \%$ & 0.076 \\
\hline Hypertensive & $60.6 \%$ & $55.4 \%$ & \\
\hline \multicolumn{4}{|l|}{ Diastolic blood pressure } \\
\hline Hypotensive & $27.8 \%$ & $33.8 \%$ & 0.085 \\
\hline Hypertensive & $37.1 \%$ & $40.1 \%$ & \\
\hline Takes blood pressure medication & $32.4 \%$ & $30.6 \%$ & 0.658 \\
\hline \multicolumn{4}{|l|}{ Cognitive functioning } \\
\hline MMSE & $27.5(2.5)$ & $26.4(3.5)$ & 0.000 \\
\hline Episodic Memory Test & $11.1(2.8)$ & $9.8(3.5)$ & 0.000 \\
\hline Symbol Letter Modalities Test & $97.9(16.1)$ & $88.6(18.1)$ & 0.000 \\
\hline National Adult Reading Test & $112.2(9.7)$ & $109.7(9.6)$ & 0.004 \\
\hline \multicolumn{4}{|l|}{ Social support } \\
\hline \multicolumn{4}{|l|}{ Living arrangements } \\
\hline Lives alone & $34.7 \%$ & $29.8 \%$ & 0.049 \\
\hline Lives with spouse & $55.6 \%$ & $54.2 \%$ & \\
\hline Social support -network & $0.73(0.20)$ & $0.68(0.22)$ & 0.005 \\
\hline Social support -help & $0.72(0.12)$ & $0.73(0.12)$ & 0.386 \\
\hline Social support-close friends & $0.91(0.22)$ & $0.88(0.26)$ & 0.098 \\
\hline \multicolumn{4}{|l|}{ Psychiatric symptoms } \\
\hline Scale for depression symptoms & $2.0(2.5)$ & $2.7(2.7)$ & 0.002 \\
\hline Anxiety scale of Goldberg & $2.3(2.1)$ & $2.5(2.0)$ & 0.195 \\
\hline Depression scale of Goldberg & $1.9(1.8)$ & $2.5(2.0)$ & 0.000 \\
\hline \multicolumn{4}{|l|}{ Personality } \\
\hline Extraversion & $5.9(3.2)$ & $5.6(3.1)$ & 0.350 \\
\hline Neuroticism & $3.1(2.8)$ & $3.0(2.9)$ & 0.744 \\
\hline \multicolumn{4}{|l|}{ Socioeconomic status } \\
\hline Years of education & $11.4(2.6)$ & $11.3(2.6)$ & 0.932 \\
\hline Occupational status & & & 0.966 \\
\hline 1: unskilled or semi-skilled & $26.9 \%$ & $26.3 \%$ & \\
\hline 2: skilled tradesmen & $10.2 \%$ & $17.0 \%$ & \\
\hline 3: white collar worker & $25.0 \%$ & $14.0 \%$ & \\
\hline 4: proprietor & $17.2 \%$ & $21.6 \%$ & \\
\hline 5: managerial/professional & $20.7 \%$ & $21.2 \%$ & \\
\hline \multicolumn{4}{|l|}{ Health habits } \\
\hline \multicolumn{4}{|l|}{ Smoking } \\
\hline Never smoked & $45.5 \%$ & $40.2 \%$ & 0.222 \\
\hline Currently smoke & $11.9 \%$ & $9.8 \%$ & \\
\hline Inactivity scale & $5.7(3.8)$ & $8.2(4.4)$ & 0.000 \\
\hline
\end{tabular}

KEY POINTS

- Mortality among elderly men was estimated to be more than twice that of women, after adjusting for a wide range of other variables.

- Apart from sex, the main predictors of mortality were physical health and cognitive performance.

- Social support, psychiatric symptoms, and socioeconomic status did not add to the prediction of mortality once adjustment was made for health and cognitive performance.

\section{STATISTICAL METHODS}

The Cox proportional hazards model was used to select the predictors of mortality. In selecting the best set of predictors, age and sex were included in all models. The strategy adopted involved forward, stepwise selection of variables within each of the blocks of predictors defined above (physical health, cognitive functioning, social support, psychiatric symptoms, personality, socioeconomic status, health behaviours). The process was conducted for the total sample and for men and women separately. For the total sample, models were tested with interaction terms between sex and each of the predictor variables and between age (coded $<80$ years and $80+$ ) and each of the predictors. Linearity assumptions in the interval variables were investigated by recoding these variables into quintiles, treating them as categorical variables and using polynomial contrasts in the Cox regressions. Proportionality assumptions were also tested and found to hold. The set of variables that were significantly associated with survival in any one of these analyses was then included in a set of predictors to form the final model. All possible two way interactions in this model were tested and because of the large number of such terms a level of 0.01 was adopted. None was significant. Analyses were made using SPSS for Windows, version 7.5.

As a further check on the effect of missing values, a data set was constructed in which missing values were replaced by imputed values, estimated using the multiple linear regression method of the MVA procedure in SPSS. The selection procedure described above was repeated on this data set. Unless otherwise indicated, results from this analysis confirmed those already obtained.

\section{Results}

At Wave 2, an average of 3.6 years after Wave 1, 341 men and 374 women were known to be alive, while $110(24.1 \%)$ males and $62(14.1 \%)$ women were known to have died, with no information being available for the remaining five men and five women. Figure 1 shows the observed survival curves in days from the time of the Wave 1 assessment, for men and women separately.

Table 1 shows the means and standard deviations for each of the predictor variables considered, for those who died and those who 
survived until Wave 2. At Wave 1, those who died during the subsequent 3.6 years were older and more likely to be male, were in poorer health and more disabled, had poorer cognitive functioning, were more depressed, showed greater inactivity, and had poorer social networks (even though fewer lived alone). However, there were no differences on the anxiety scale, in personality scores, in socioeconomic status or smoking history. Some subjects were unable to complete the interview, especially the personality questionnaire. These persons tended to be older, had greater disability, were less active, were more likely to have systolic hypotension, and had poorer cognitive scores on those tasks that were completed.

Table 2 shows the variables that were retained in the final models. Each selected variable was significant in at least one of the models. Physical health variables selected were: self reported general health, activities of daily living, total number of illnesses, and systolic blood pressure. Once physical health was controlled, the only variables chosen were the Symbol-Letter Modalities Test and the MiniMental State Examination from the cognitive functioning block, and neuroticism from the personality block. Age, self rated health, and systolic blood pressure showed significant departures from linearity and so were entered as categorical variables in the analyses. All other variables could be treated as linear in their quintiles. In table 2, the reference category for continuous predictors is either the lowest or highest quintile, and the relative risks are presented comparing the extreme categories of the lowest with the highest quintile. This method provides an indication of the "po- tency" of these predictors, as recommended by Kraemer. ${ }^{40}$ When both sexes were analysed together, none of the interaction terms with sex was found to be significant, except for systolic blood pressure by sex in the data set with imputed missing data. However, as the lack of significant findings for these interaction effects could be an effect of low statistical power, the results are also shown for men and women separately.

Age was not a significant covariate once adjustment was made for health and cognitive performance. However, if only physical health variables were controlled, mortality was significantly higher among those aged 85 and over compared with the reference group of 70-74 $(R R=2.03,95 \%$ CI $1.11,3.70)$. This relation disappeared once cognitive variables were included in the model. When men and women were analysed separately, this was particularly noticeable for men (RR for age 85+ compared with age 70-74, controlling for physical health was $2.55,95 \%$ CI $1.23,5.28$ ), while the increased mortality among older women after controlling for physical health was not significant $(\mathrm{RR}=1.98(95 \%$ CI $0.94,4.15)$ for age 85+ compared with age 70-74).

The greater mortality among men compared with women remained, no matter which other predictors were controlled. The only variables that contributed significantly to the prediction of mortality, once sex and physical health were controlled, were cognitive performance (Symbol-Letter Modalities Test in men and Mini-Mental State Examination for women), and higher neuroticism in men had a protective effect. The relation with cognitive performance remained when respondents diagnosed with

Table 2 Cox proportional hazards model: $\beta$ coefficients and relative risks adjusted for all other predictors in the final model *

\begin{tabular}{|c|c|c|c|c|c|c|}
\hline & \multicolumn{2}{|c|}{ Men and women } & \multicolumn{2}{|l|}{ Men } & \multicolumn{2}{|l|}{ Women } \\
\hline & $\beta$ & $R R \int(95 \% C I)$ & $\beta$ & $\operatorname{RRS}(95 \% C I)$ & $\beta$ & $R R \int(95 \% C I)$ \\
\hline \multicolumn{7}{|l|}{ Age (5 year age groups) } \\
\hline $70-74$ (reference) & - & 1.00 & - & 1.00 & - & 1.00 \\
\hline $75-79$ & -0.19 & $0.82(0.52,1.29)$ & -0.13 & $0.88(0.51,1.53)$ & -0.47 & $0.63(0.28,1.42)$ \\
\hline $80-84$ & -0.06 & $0.96(0.57,1.56)$ & 0.06 & $1.07(0.58,1.95)$ & -0.30 & $0.74(0.28,1.96)$ \\
\hline $85+$ & 0.44 & $1.57(0.85,2.89)$ & 0.68 & $1.98(0.94,4.15)$ & 0.10 & $1.11(0.37,3.36)$ \\
\hline Sex & & & - & - & - & - \\
\hline Female (reference) & - & 1.00 & & & & \\
\hline Male & 0.93 & $2.72(1.83,4.04)$ & & & & \\
\hline \multicolumn{7}{|l|}{ General health } \\
\hline Excellent (reference) & - & 1.00 & - & 1.00 & - & 1.00 \\
\hline Good & -0.29 & $0.75(0.44,1.28)$ & -0.29 & $0.75(0.39,1.44)$ & -0.30 & $0.74(0.28,1.97)$ \\
\hline Fair & -0.17 & $0.81(0.44,1.47)$ & -0.01 & $0.99(0.47,2.07)$ & -0.51 & $0.60(0.20,1.83)$ \\
\hline Poor & 0.74 & $1.82(0.85,3.87)$ & 0.97 & $2.63(1.00,6.98)$ & 0.29 & $1.33(0.35,5.14)$ \\
\hline ADL & $0.21 \dagger$ & & $0.11 \dagger$ & & $0.43 \dagger$ & \\
\hline 0 (reference level) & & 1.00 & & 1.00 & & 1.00 \\
\hline $4+$ (upper quintile) & & $2.299(1.30,3.75)$ & & $1.52 \uparrow(0.79,2.94)$ & & $5.52 \rrbracket(1.96,15.54)$ \\
\hline Total illnesses & $0.29 \dagger$ & & $0.33 \dagger$ & & $0.29 \dagger$ & \\
\hline None (reference level) & & 1.00 & & 1.00 & & 1.00 \\
\hline $6+$ (upper quintile) & & $3.159(1.74,5.70)$ & & $3.45 \rrbracket(1.71,6.98)$ & & $3.21 \rrbracket(1.00,0.29)$ \\
\hline \multicolumn{7}{|l|}{ Systolic blood pressure } \\
\hline Hypotensive & 0.51 & $1.66(0.92,3.00)$ & 0.23 & $1.26(0.62,2.57)$ & 1.46 & $4.30(1.47,12.56)$ \\
\hline Normotensive (reference) & - & 1.00 & - & 1.00 & - & 1.00 \\
\hline Hypertensive & 0.08 & $1.09(0.72,1.64)$ & 0.05 & $1.05(0.63,1.73)$ & 0.31 & $1.36(0.63,2.96)$ \\
\hline SLMT-IQ & $0.22 \ddagger$ & & $0.34 \ddagger$ & & $-0.11 \ddagger$ & \\
\hline$\geqslant 112$ (reference level) & & 1.00 & & 1.00 & & 1.00 \\
\hline$<84$ (lowest quintile) & & $2.42 \Phi(1.27,4.62)$ & & $3.86 \rrbracket(1.76,8.45)$ & & $0.66 \rrbracket(0.20,2.18)$ \\
\hline MMSE & $0.16 \ddagger$ & & $0.07 \ddagger$ & & $0.36 \$$ & \\
\hline 30 (reference level) & & 1.00 & & 1.00 & & 1.00 \\
\hline$<24$ (lowest quintile) & & $1.88 \Phi(1.05,3.12)$ & & $1.34 \rrbracket(0.67,2.50)$ & & $4.219(1.43,12.41)$ \\
\hline Neuroticism & $-0.16 \dagger$ & & $-0.21 \dagger$ & & $0.02 \dagger$ & \\
\hline 0 (reference level) & & 1.00 & & 1.00 & & 1.00 \\
\hline $6+$ (upper quintile) & & $0.53 \rrbracket(0.31,0.90)$ & & $0.42 \uparrow(0.22,0.80)$ & & 1.09 व $(0.40,2.99)$ \\
\hline
\end{tabular}

* Results for factors that add significantly to the model are indicated in bold. $+\beta$ associated with an increase in the predictor of one quintile. $\ddagger \beta$ associated with a decrease in the predictor of one quintile. $\$$ Relative risk for a person in the category nominated, compared with the reference category. ๆ Relative risk calculated as $\exp (4 \times \beta) ; 95 \%$ CI calculated as $\exp 4 \times(\beta \pm 1.96 \times \operatorname{se}(\beta))$. 
dementia were excluded from the analysis. The most important physical health variables were total number of illnesses for both men and women, poor self rated health in men, and activities of daily living and systolic hypotension in women.

\section{Discussion}

Excess mortality in men at all ages is well recognised, ${ }^{41}$ and this study found that men were more than twice as likely to die as women, adjusting for other covariates. Most studies of the predictors of mortality, however, either report men and women separately, not comparing their adjusted risks, ${ }^{17} 192241$ or fail to report it. ${ }^{42}$ Our results show that the sex difference is not mediated by any of the covariates we included. There is evidence that hormonal exposures earlier in life are important, because castrated men have a lower mortality than intact men, and even a lower mortality than intact women. ${ }^{43}$ However, hormonal exposures may affect other more proximal health or psychosocial predictors of mortality in old age, and the identity of these other predictors remains a mystery.

Age was not a significant covariate once adjustment was made for health and cognitive performance, but was significant if only physical health was controlled, especially for men in the oldest age group. Cognitive performance, especially speeded tasks such as the SLMT, deteriorates rapidly with age. ${ }^{38}$ If cognitive impairment is linked to terminal decline, it may be a stronger predictor of mortality than age over short periods of time. Some other studies on predictors of mortality continued to find a strong age effect even when a wide range of other covariates were included. ${ }^{17}{ }^{19}$ However, these studies had a longer follow up than ours. When mortality is predicted over long periods, age may be a better predictor than baseline health measures that were taken many years previously.

When men and women were analysed separately, the general pattern of the results was the same, in that the variables selected came from the physical health and cognitive functioning domains. However, the specific variables selected from within these domains were different. For example, self rated health was selected as a physical health predictor for men, while for women it was disability in activities of daily living. A number of other studies have found that self rated health is a better predictor of mortality for men than for women. ${ }^{1}$ Similarly, in the domain of cognitive functioning, the Symbol-Letter Modalities Test was selected for men, while the Mini-Mental State Examination was selected for women. The finding that a test of mental speed is a good predictor for men confirms an earlier study using a male only sample. ${ }^{3}$

Neuroticism was not detected as a predictor of mortality in univariate analyses, consistent with earlier studies. ${ }^{22}{ }^{25}$ However, it did emerge as a significant protective factor in the multivariate model, both in the total sample and in men only. The relative risk for other health variables changed only slightly whether or not neuroticism was in the model. We have earlier reported data from this study showing that neuroticism is correlated with subjective health, but not with objective measures. ${ }^{30}$ Thus, neuroticism seems to be associated with a negative evaluation of one's health. In the multivariate model, neuroticism is a confounding variable that corrects for a tendency to misrepresent health problems. This is illustrated for a self rating of poor general health among men. The relative risk was estimated as 2.11 $(0.82,5.48)$ in the model without neuroticism and as $2.63(1.00,6.98)$ when neuroticism was included.

Hypotension, both systolic and diastolic, has been shown to be a predictor of mortality, although there remains considerable debate as to whether it is simply a sign of disease or frailty. ${ }^{44-46}$ The relation in this study remained after controlling for hypertensive medication, and was much stronger in women than in men. Simons et al found that mortality was generally associated with increasing blood pressure, ${ }^{19}$ but among the very old, there was a suggestion that it was associated with both hypertension and hypotension. As there was a tendency for those with hypotension to fail to complete the interview, possibly because of fatigue and frailty, and as mortality was higher among those with missing data, it is not surprising that the effect was strongly confirmed in analyses on the data set with imputed missing values.

Some of the negative results in the study are worth commenting on. Smoking has been found in some other studies to be significant, including two other Australian studies. ${ }^{17}{ }^{19}$ These studies included younger elderly subjects (aged 60-69), suggesting that, if smoking related mortality is higher in this age group, the present sample could represent a survival elite. Another possibility is that mortality is related to total exposure, in which case the measures used in this study of past and current smoking status may have been inadequate to detect a relation. The other health habit examined, inactivity, was a univariate predictor of mortality, but the effect disappeared in the multi-variate model, implying that inactivity is simply a reflection of physical illness and disability or a general slowing that is reflected in performance on the speeded cognitive test.

Depression was also a univariate predictor of mortality, but was not selected in the multivariate model. The major risk factor for depression in old age is physical ill health, ${ }^{20}$ so the effect reported in some studies could be because of inadequate control for physical health.

Socioeconomic status did not even emerge as a univariate predictor, although lower socioeconomic levels and greater inequality within populations have been associated with higher mortality in many studies. ${ }^{27}$ 47-49 This study, however, was conducted in a comparatively homogeneous community that has a much higher level of education and occupational status than the rest of Australia, with comparatively few people having only primary school education or working in unskilled occupations.

The only social support variable found to be significant at the univariate level was the size of 
the social network, but neither it nor any of the other social support variables was selected in the multivariate model. It should be noted that the items measuring social support in this study were more extensive in their coverage than those used in surveys reporting a protective effect. Other Australian studies have also shown no or only a weak association of social support variables with mortality. ${ }^{17-19}$

In conclusion, the strength of this study lies in the wide range of psychosocial variables considered, together with its allowance for confounding. While many of these variables had simple associations with mortality, once other variables were controlled it was only the cognitive functioning variables that retained an association.

Funding: this work was supported by a grant from the Australian Rotary Health Research Fund.

Conflicts of interest: none.

Valuable help with the survey was provided by Ruth Scott, Suzanne Dee, Susan Lindsay, and Andrew Mackinnon.

1 Idler EL, Benyamini Y. Self-rated health and mortality: A review of twenty-seven community studies. 7 Health Soc Behav 1997;38:21-37.

2 Gale CR, Martyn CN, Cooper C. Cognitive impairment and mortality in a cohort of elderly people. BMF 1996;312: 608-11.

3 Swan GE, Garmelli D, LaRue A. Performance on the Digit Symbol Substitution Test and 5-year mortality in the Western Collaborative Group Study. Am f Epidemiol 1995;141: 32-40.

4 Berr C, Dartigues JF, Alpérovitch A. Cognitive performance and three-year mortality in the PAQUID elderly study. Rev and three-year mortality in the PAQUID eld

5 Blazer DG. Social support and mortality in an elderly community population. Am F Epidemiol 1982;115:684-94.

6 Campbell AJ, Diep C, Reinken J, et al. Factors predicting mortality in a total population sample of the elderly. F Epidemiol Community Health 1985;39:337-42.

7 Small BJ, Bäckman L. Cognitive correlates of mortality: Evidence from a population-based sample of very old adults. Psychol Aging 1997;12:309-13.

8 Berkman LF, Syme L. Social networks, host resistance, and mortality: A nine-year follow-up study of Alameda county residents. Am ₹ Epidemiol 1979;109:186-204.

9 House JS, Robbins C, Metzner HL. The association of social relationships and activities with mortality: prospective evidence from the Tecumseh Community Health Study. Am ₹ Epidemiol 1982;116:123-40.

10 Welin L, Tibblin G, Svärdsudd K, et al. Prospective study of social influences on mortality. Lancet 1985:i:915-18.

11 Seeman TE, Kaplan GA, Knudsen L, et al. Social network ties and mortality among the elderly in the Alameda county study. Am F Epidemiol 1987;126:714-23.

12 Hanson BS, Isacsson S-O, Janzon L, et al. Social network and social support influence mortality in elderly men. $A m \mathcal{F}$ Epidemiol 1989;130:100-11.

13 Schoenbach VJ, Kaplan BH, Fredman L, et al. Social ties and mortality in Evans county, Georgia. Am $\mathcal{F}$ Epidemio 1986;123:577-91

14 Hirdes JP, Forbes WF. The importance of social relationships, socioeconomic status and health practices with respect to mortality among healthy Ontario males. $f$ Clin Epidemiol 1992;45:175-82.

15 Steinbach U. Social networks, institutionalization, and mortality among elderly people in the United States. F Geronto 1992;47:S183-90.

16 Shahtahmasebi S, Davies R, Wenger GC. A longitudinal analysis of factors related to survival in old age. Gerontologist 1992;32:404-13.

17 McCallum J, Shadbolt B, Wang D. Self-rated health and survival: A 7-year follow-up study of Australian elderly. $A m$ F Public Health 1994;84:1100-5.

18 Jorm AF, Henderson AS, Kay DWK, et al. Mortality in relation to dementia, depression and social integration in an elderly community sample. International fournal of Geriatric Psychiatry 1991;6:5-11.
19 Simons LA, Friedlander Y, McCallum J, et al. Predictors of mortality in the prospective Dubbo study of Australian elderly. Aust NZ F Med 1996;26:40-8.

20 Jorm AF. The epidemiology of depressive states in the elderly: Implications for recognition, intervention and prevention. Soc Psychiatry Psychiatr Epidemiol 1995;30:53-9.

21 Bickel $\mathrm{H}$. Psychiatric illness and mortality among the elderly: findings of an epidemiological study. In: Cooper B, ed. Psychiatric epidemiology. London: Croom Helm, 1987: 192-211.

22 Huppert FA, Whittington JE. Symptoms of psychological distress predict 7-year mortality. Psychol Med 1995;25: 1073-86.

23 Murphy JM, Monson RR, Olivier DC, et al. Affective disorders and mortality. Arch Gen Psychiatry 1987;44:473-80.

24 Rorsman B, Hagnell O, Lanke J. Mortality in the Lundby study. Neuropsychobiology 1882;8:188-97.

25 Almada SI, Zonderman AB, Shekelle RB, et al. Neuroticism and cynicism and risk of death in middle-aged men: The Western Electric study. Psychosom Med 1991;53:165-75.

26 Friedman HS, Tucker JS, Schwartz JE, et al. Psychosocial and behavioral predictors of longevity. Am Psychol 1995;50 69-78.

27 Marmot MG, Kogevinas M, Elston MA. Social/economic status and disease. Annu Rev Public Health 1987;8:111-35.

28 Finucane P, Giles LC, Withers RT, et al. Exercise profile and subsequent mortality in an elderly Australian population. Aust NZ 7 Public Health 1997;21:155-8.

29 Henderson AS, Jorm AF, Mackinnon AJ, et al. The prevalence of depressive disorders and the distribution of depressive symptoms in later life: A survey using Draft ICD-10 and DSM-III-R. Psychol Med 1993;23:719-29.

30 Jorm AF, Christensen H, Henderson S, et al. Neuroticism and self-reported health in an elderly community sample. Personality and Individual Differences 1993;15:515-21.

31 Gilmore C, Green BH, Copeland JRM, et al. Blood pressure as a risk factor for depression in elderly people: a prospective study. Acta Psychiatr Scand 1995;91:126-9.

32 Folstein MF, Folstein SE, McHugh PR. "Mini-Mental State" A practical method for grading the cognitive state of patients for the clinician. $\mathcal{F}$ Psychiatr Res 1975;12:189-98.

33 Jorm AF. Use of informants' reports to study memory changes in dementia. In: Bäckman L, ed. Memory function ing in dementia. Amsterdam: Elsevier, 1992:267-82.

34 Christensen H, Jorm AF, Henderson AS, et al. The relationship between health and cognitive functioning in an elderly community sample. Age Ageing 1994;23:204-12.

35 Nelson HE. National adult reading test (NART): test manual. Windsor, Berkshire: NFER-Nelson, 1982.

36 Henderson AS, Byrne DG, Duncan-Jones P. Neurosis and the social environment. Sydney: Academic Press, 1981.

37 Goldberg D, Bridges K, Duncan-Jones P, et al. Detecting anxiety and depression in general medical settings. $B M \mathcal{F}$ 1988;297:897-9.

38 Eysenck SBG, Eysenck HJ, Barrett P. A revised version of the psychoticism scale. Personality and Individual Differences 1985;6:21-9.

39 Christensen $\mathrm{H}$, Korten A, Jorm AF, et al. Activity levels and cognitive functioning in an elderly community sample. Age Ageing 1996;25:72-80.

40 Kraemer HC, Kazdin A, Offord DR, et al. Coming to terms with the terms of risk. Arch Gen Psychiatry 1997;54:33743.

41 Australian Institute of Health and Welfare. Australia's health 1996. Canberra: Australian Government Publishing Service, 1996.

42 Jagger C, Clarke M. Mortality risks in the elderly: Five-year follow-up of a total population. Int $\mathcal{F}$ Epidemiol 1988;17: 111-14

43 Hamilton JB, Mestler GE. Mortality and survival: comparison of eunuchs with intact men and women in a mentally retarded population. F Gerontol 1969;24:395-411.

44 Vatten LJ, Holmen J, Krüger $\varnothing$, et al. Low blood pressure and mortality in the elderly: a 6 -year follow-up of 18,022 Norwegian men and women age 65 years and older. Epidemiology 1995;6:70-3.

45 Busby WJ, Campbell AJ, Robertson MC. Is low blood pressure in elderly people just a consequence of heart disease and frailty? Age Ageing 1994;23:69-74.

46 Langer RD, Ganiats TG, Barrett-Connor E. Factors associated with paradoxical survival at higher blood pressures in the very old. Am f Epidemiol 1991;134:29-38.

47 Smith GD. Income inequality and mortality: why are they related. BMF 1996;312:987-8.

48 Olausson PO. Mortality among the elderly in Sweden by social class. Soc Sci Med 1991;32:437-40.

49 Martelin T. Mortality by indicators of socioeconomic status among the Finnish elderly. Soc Sci Med 1994;38:1257-78. 